Research Article

\title{
Situational Analysis and Trend of COVID-19 Virus in India
}

\author{
Sujeet Kumar Singh', $\underline{\text { SN Sharma }}^{2}$ \\ ${ }^{1,2}$ National Centre for Disease Control, Ministry of Health \& FW, Govt. of India, 22 Sham Nath Marg, Delhi, India. \\ DOI: https://doi.org/10.24321/0019.5138.202017
}

\section{I $\quad \mathbf{N} \quad \mathbf{F} \quad \mathbf{O}$}

\section{Corresponding Author:}

SN Sharma, National Centre for Disease Control, Ministry of Health \& FW, Govt. of India, 22 Sham Nath Marg, Delhi, India.

E-mail Id:

drsns.nvbdcp@gmail.com

Orcid Id:

https://orcid.org/0000-0001-8569-1661

How to cite this article:

Singh SK, Sharma SN. Situational Analysis and Trend of COVID-19 Virus in India. J Commun Dis 2020; 52(2): 38-45.

Date of Submission: 2020-05-26

Date of Acceptance: 2020-06-04

\author{
$\begin{array}{llllllll}\mathbf{A} & \mathbf{B} & \mathbf{S} & \mathbf{T} & \mathbf{R} & \mathbf{A} & \mathbf{C} & \mathbf{T}\end{array}$
}

COVID-19 virus has emerged a serious threat to the universe engulfing lakhs of human lives across the world. This is in the form of very unique and virulent deadly disaster on the earth spreading disease so fast being contagious in nature that it has given no time to medical professional to think and prepare to fight against this deadly disease. Loss of heavy lives in the world can not be forgotten for long in the history as it has been reported from USA, Spain, Italy and France. It is said to have originated initially from Wuhan of China and spread over to other parts of the world. The point of spread or transmission has become a matter of debate and controversy around the world as to whether its transmission has happened due to man to man contact after making shift from wild animals i.e. bats, pangolins (food market) or it was as a result of some leakage from a testing laboratory in Wuhan.

Unfortunately, no drug or vaccine has been yet found effective to deal with this deadly virus. The spread of this deadly virus is very rapid in the community due to its very high contagious nature and fast multiplication. There have been some updates in the knowledge about the clinical signs and symptoms of this virus across the world. However, the disease is changing its epidemiological profile with disease spectrum and making difficult to deal with it. An attempt has been made in this manuscript to undertake the situational analysis and study the trend of COVID-19 in Indian perspective.

Keywords: Epidemiology, COVID-19, Severe Acute Respiratory Syndrome (SARS) and Middle East Respiratory Syndrome (MERS), Syndrome-Related Corona Viruses (SARSr-CoV)

\section{Introduction}

The Coronavirus belongs to the family of virus that causes viral pneumonia including fever, breathing difficulty, and lung infection. These viruses are commonly present in animals across the globe, but very rarely these are known to affect human beings. ${ }^{1} \mathrm{~A}$ Public Health Emergency was declared by the World Health Organization on 30 January, 2020 due to the outbreak of this virus in the world and named it as a pandemic on 11 March, 2020. ${ }^{2-3}$ The virus is primarily spread between people during close contact, most often via small droplets produced by coughing, sneezing, and talking. The droplets usually fall to the ground or onto surfaces rather than travelling through air over long distances. ${ }^{4}$ It is most contagious during the first three days after the onset of symptoms, although spread is possible before symptoms appear and from people who do not show symptoms. ${ }^{5}$ 
Common symptoms include fever, cough, fatigue, shortness of breath, and loss of smell. Complications may include pneumonia and acute respiratory distress syndrome. The time from exposure to onset of symptoms is typically around five days but may range from two to fourteen days. There is no known vaccine or specific antiviral treatment. Primary treatment is symptomatic and supportive therapy.

The first case of the COVID-19 pandemic in India was reported on 30 January 2020, originating from China. As of 24 May 2020, the Ministry of Health and Family Welfare have confirmed a total of 131,868 cases, 54,441 recoveries and 3,861 deaths in the country. ${ }^{6}$ India currently has the fourth largest number of confirmed cases in Asia with number of cases breaching the 100,000 mark on 19 May $2020 .{ }^{7}$ The highest single day surge in new cases was recorded on 23 May 2020, when 6629 cases were reported. ${ }^{8}$ India's case fatality rate is relatively lower at $3.09 \%$, against the global $6.63 \%$ as of 20 May $2020 .^{9}$ Five cities account for around half of all reported cases in the country - Mumbai, Delhi, Ahmedabad, Chennai and Pune. ${ }^{10}$

As of 24 May 2020, two regions, Sikkim and Lakshadweep have not reported a case. Large number of cases has been reported from Delhi, Karnataka, Kerala, Maharashtra, Rajasthan, Tamil Nadu, Telangana and Uttar Pradesh.

\section{Incubation Period}

Symptoms of COVID-19 may appear in as few as 2 days or as long as 14 (estimated ranges vary from 2-10 days, 2-14 days, and 10-14 days), during which the virus is contagious but the patient does not display any symptoms (asymptomatic transmission). Transmission from such a carrier is considered possible. ${ }^{11}$ Initially, the common symptoms of COVID-19 included fever, dry cough and breathing shortness. However, with the changing clinical profile, other signs and symptoms like fatigue, respiratory sputum production (phlegm), loss of the sense of smell, loss of taste, muscle and joint pain, sore throat, headache, chills, vomiting, and rash were included in the disease spectrum. ${ }^{12-14}$

\section{Transmission}

COVID-19 is a new disease, and many of the details of its spread are still under investigation. It is said to happen and become contagious in two or more people when come in close proximity (two metres or six feet) via small droplets produced during coughing, sneezing, or talking. Contaminated droplets exhaled by infected people are then inhaled into the lungs, or settle on other people's faces to cause new infection. The droplets are relatively heavy, usually fall to surfaces, and do not travel far through the air.

People are most infectious when they show symptoms (even mild or non-specific symptoms), but may be infectious for up to two days before symptoms appear (pre-symptomatic transmission). They remain infectious an estimated seven to twelve days in moderate cases and an average of two weeks in severe cases. When the contaminated droplets fall to floors or surfaces they can, though less commonly, remain infectious if people touch contaminated surfaces and then their eyes, nose or mouth with unwashed hands.

\section{Epidemiological Situation}

COVID-19 originated from Wuhan in China and spread over more than 200 countries across the world. The highly affected countries include USA, Brazil, Russia, Spain, UK, Italy France, Germany, Turky, Iran and India reporting maximum number of corona cases. There have been a total number of $5,418,513$ cases in the world as per world corona meter with $2,254,432$ cases (41.60\%) recovered. However, there is report of 344, 207 deaths (Fatality rate - 6.3\%) related with Corona virus based on the data of the world. Eleven countries contributed $72.21 \%$ of the total cases and $79.90 \%$ deaths reported in the world till 24.5.2020. However, the Recovery rate in these eleven countries have been $36.68 \%$ with test positivity rate as $8.9 \%$. Maximum number of deaths has been reported in USA with 98,683 with CFR and test positivity rate as $5.92 \%$ and $11.61 \%$. The recovered cases have been less in numbers with only $26.81 \%$. After going through the data, it is observed that the case recovery rate has been between $26.81 \%$ (USA) to $89.06 \%$ (Germany) and case fatality ranged from $1.02 \%$ (Russia) to $15.52 \%$ (France). Highest deaths per million population has been reported in UK and Italy with 541 deaths per million population, while India has reported 3 per million population. The world data showed an average of 44 deaths per million population till 24.5.2020. The details of the corona cases reported in 11 highly affected countries are shown in table 1.

Table I.Details of Covid- 9 Cases in some high endemic countries

\begin{tabular}{|c|c|c|c|c|c|c|c|c|}
\hline $\begin{array}{c}\text { Country \& } \\
\text { territory }\end{array}$ & Confirmed & Recovered & Deaths & $\begin{array}{c}\text { Case } \\
\text { Fatality } \\
\text { Rate } \\
\text { (CFR) \% }\end{array}$ & $\begin{array}{c}\text { Deaths/ } \\
\mathbf{1} \text { million }\end{array}$ & Total Tests & $\begin{array}{c}\text { Test/ } \\
\mathbf{1 M}\end{array}$ & $\begin{array}{c}\text { Test } \\
\text { Positivity } \\
\text { rate (\%) }\end{array}$ \\
\hline United States & $1,666,828$ & $\begin{array}{c}446,914 \\
(26.81 \%)\end{array}$ & 98,683 & 5.92 & 298 & $14,357,969$ & 43,404 & 11.61 \\
\hline
\end{tabular}




\begin{tabular}{|c|c|c|c|c|c|c|c|c|}
\hline Brazil & 349,113 & $\begin{array}{c}142,587 \\
(40.84 \%)\end{array}$ & 22,165 & 6.34 & 104 & 735,224 & 3,461 & 47.48 \\
\hline Russia & 344,481 & $\begin{array}{c}113,299 \\
(32.88 \%)\end{array}$ & 3541 & 1.02 & 24 & $8,600,000$ & 58,933 & 4.0 \\
\hline Spain & 282,370 & $\begin{array}{c}196,958 \\
(69.75 \%)\end{array}$ & 28,678 & 10.15 & 613 & $3,556,567$ & 76,071 & 7.9 \\
\hline UK & 257,154 & $\mathrm{~N} / \mathrm{A}$ & 36,675 & 14.26 & 541 & $3,348,507$ & 49,352 & 7.7 \\
\hline Italy & 229,327 & $\begin{array}{c}138,840 \\
(60.54 \%)\end{array}$ & 32,735 & 14.27 & 541 & $3,391,188$ & 56,080 & 6.7 \\
\hline France & 182,469 & $\begin{array}{c}64,547 \\
(35.37 \%)\end{array}$ & 28,332 & 15.52 & 434 & $1,384,633$ & 21,218 & 13.2 \\
\hline Germany & 179,986 & $\begin{array}{c}160,300 \\
(89.06 \%)\end{array}$ & 8,366 & 4.64 & 100 & $3,595,059$ & 42,923 & 5.0 \\
\hline Turky & 155,686 & $\begin{array}{c}117,602 \\
(75.53 \%)\end{array}$ & 4,308 & 2.76 & 51 & $1,807,673$ & 21,458 & 8.6 \\
\hline Iran & 133,521 & $\begin{array}{c}104,072 \\
(77.94 \%)\end{array}$ & 7,359 & 5.51 & 88 & 781,286 & 9,315 & 17.0 \\
\hline India & 131,868 & $\begin{array}{c}54,441 \\
(41.28 \%)\end{array}$ & 3,867 & 2.93 & 3 & $2,943,421$ & 2,135 & 4.5 \\
\hline $\begin{array}{c}\text { Total of above } \\
11 \text { countries }\end{array}$ & $3,912,808$ \\
$(72.21 \%)$
\end{tabular}

*Data Source : Worldometer

\section{Indian COVID-I 9 Situation}

India has become $11^{\text {th }}$ number in the world among the countries reporting maximum number of corona cases. In India, a total of 131,868 cases, 54,441 recoveries and 3,861 deaths in the country have been reported till 24.5.2020. The number of cases and deaths reported due to corona till 24.5.2020 is shown in Figure 1.

Trend of COVID-19 Cases and Deaths (Cumulative since $4^{\text {th }}$ March 2020)

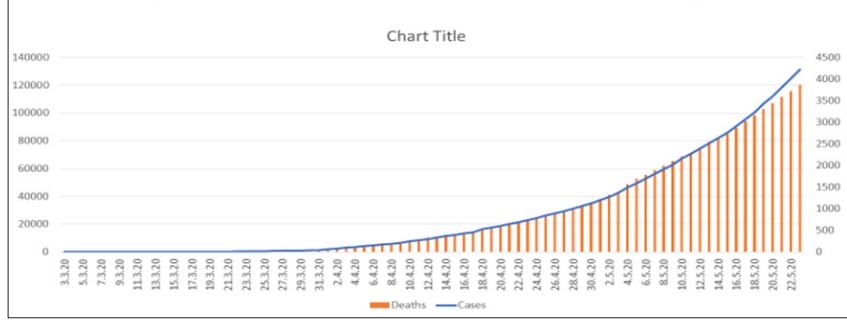

Figure I.Trend of Covid- 19 cases and deaths

The states of Maharashtra, Gujarat, Delhi, Tamil Nadu, Madhya Pradesh, West Bengal, Rajasthan and Uttar Pradesh are still reporting maximum number of cases. The incidence of COVID-19 is so high and confined to only 8 states hat the data received from these states shows the contribution of $84.83 \%$ of total cases and $93.22 \%$ to the total deaths reported in the country. $82.78 \%$ of the total cases reported confirmed cases in these 8 states have also recovered. Case fatality has been about 3.0 in the country. However, the state of west Bengal and Gujarat have shown CFR as $7.78 \%$ and $6.07 \%$. Although, the number of deaths is quite high in Maharashtra as 1577 deaths but, with CFR has been reported as 3.34\%. Tamil Nadu has reported 15512 cases with CFR as low with $0.66 \%$. The details of the corona cases reported in 8 highly affected states are shown in table 2 .

All efforts were made at the very beginning to screen and quarantine all international passengers coming from China and other COVID affected countries. However, human to human transmission has been reported initially in small numbers confined to small clusters. The Jamati episode at Nizamuddin is also said have contributed upsurge of the cases across the country. A large crowd of migratory labours across the country, their logistics arrangements i.e. shelter 
and food arrangements by the respective states has also attributed to the transmission of COVID-19 in the country. Workers dealing with the essential services and frontline health workers including police personnel have also been deployed and had the risk of transmission. Many cases occurred due to negligence of the people hiding their past travel history and hiding themselves thereby contributing in the transmission of corona virus.

The day wise details of the reported corona cases and death is shown in figure 2.

After going through the number of confirmed cases in the country, it is observed that upto 17 April 2020 (less than 1000 cases per day), between 18-30 April (less than 2000 cases per day ), between 1-3 May (less than 3000 cases per day), between 4-15 April (less than 4000 cases per day ), between 16-18 May (less than 5000 cases per day ) and between 19 - 23 May (nearly 6000 cases per day) have been reported in the country.

From 1 to 8 April, the cases starting increasing and there have been daily reporting of corona confirmed cases between $600-700$ cases. The day of $9^{\text {th }}$ April onward, there have been reporting of more than 800 cases till 14.4.2020, 21th April onwards, nearly 1500 cases per day and till 30.4.2020, there have been less than 2000 cases per day. Sharp increase in number of cases was seen from $1^{\text {st }}$ to $3^{\text {rd }}$ May increasing from 2000 to 3000 cases per day. From $3^{\text {rd }}$ to 9th May, more than 3000 cases were have been reported. After that nearly 4000 cases were touched by $15^{\text {th }}$ May 2020. Till 23.5.2020, a steep rise in the number of corona cases has been reported.

Table 2.Details of Covid- 9 Cases in some high endemic States

\begin{tabular}{|c|c|c|c|c|}
\hline Country \& territory & Confirmed & Deaths & Recovered & CFR \\
\hline Maharashtra & 47190 & 1577 & 13404 & 3.34 \\
\hline Tamil Nadu & 15512 & 103 & 7491 & 0.66 \\
\hline Gujarat & 13664 & 829 & 6169 & 6.07 \\
\hline Delhi & 12910 & 231 & 6267 & 1.79 \\
\hline Rajasthan & 6742 & 160 & 3786 & 2.37 \\
\hline Madhya Pradesh & 6371 & 281 & 3267 & 4.41 \\
\hline Uttar Pradesh & 6017 & 155 & 3406 & 2.58 \\
\hline West Bengal & 3459 & 269 & 1281 & 7.78 \\
\hline Total of above 8 states & $\begin{array}{c}111,865 \\
(84.83 \%)\end{array}$ & $\begin{array}{c}3605 \\
(93.22 \%)\end{array}$ & $\begin{array}{c}45071 \\
(82.78 \%)\end{array}$ & 3.22 \\
\hline India Total (24.5.2020) & 131,868 & 3867 & 54441 & 2.93 \\
\hline
\end{tabular}

*Data Source: Worldometer

\section{Daily Trend of COVID-19 Cases and Deaths (Since $4^{\text {th }}$ March 2020)}

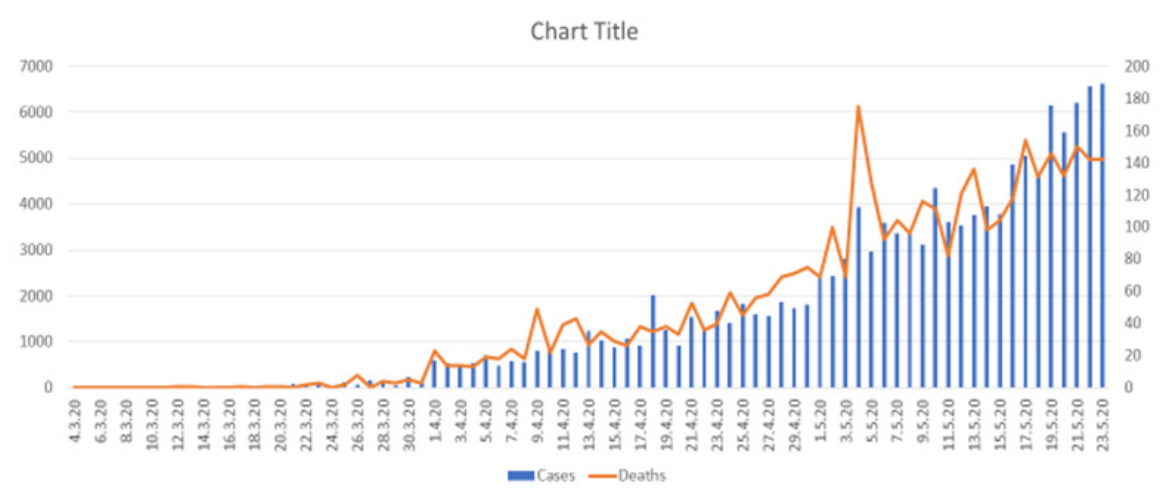

Figure 2.Daily Trend of Covid-19 cases and deaths 


\section{Epidemiological Indicators}

\section{Testing and Detection Rates}

Initially, it started initially with 15 labs. with the NCDC and ICMR network and then expended through some medical colleges with proper capacity building and commercially available testing kits. The number of diagnostic labs. in the country has been now increased to 220 including private labs approved by ICMR for undertaking RNA based RT-PCR test. Presently, an average of 15,000 to 20,000 test are being performed for detection of COVID-19. Presently, there is capacity to undertaking more than 1 lakh tests in a day with the augmentation of diagnostic facilities. Daily trend of covid-19 tests conducted is shown in figure 3 .

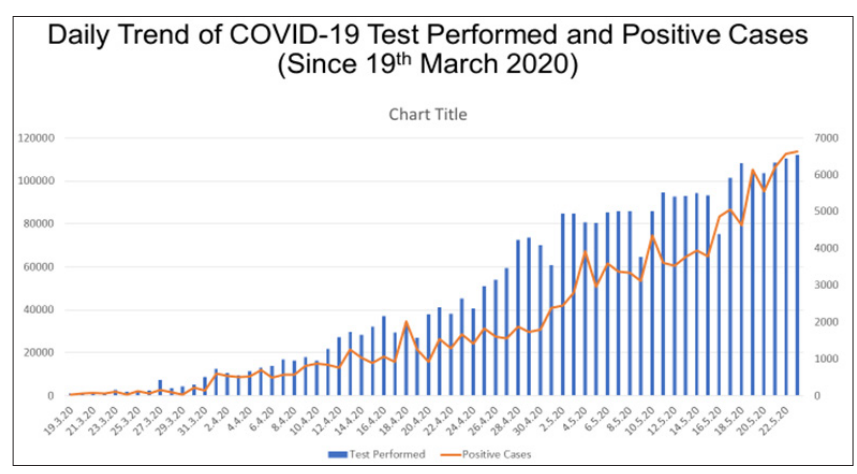

Figure 3.Daily Trend of Covid-19 Test Performed and positive cases

After going through the data on the tests conducted and detected cases, it is observed that till 11.4.2020, there were less than 20,000 tests per day with less detection of less than 1000 cases. There have been more less than 2000 positive cases till 25.4.2020, when the number of test conducted were increased up to 40,000 per day. The testing capacity was increased to 60,000 per day till 1.5 .2020 with case detection of more that 2000 positive cases. Till 17.5.2020, testing has been done more that 80,000 per day and the cases reported have been above $3000-4000$ plus cases per day. After that the number of tests have been more than one lakh with the daily reporting more than 5000 cases per day.

\section{Virus Reproduction Rate (Ro)}

The reproduction rate, or RO (pronounced R-naught), of a virus is a measure of its transmission or the number of new infections generated by each case. An RO rate of 1 can be expressed as the average that each infected person will infect one other person after contracting each other. In case, Reproduction rate of less than one that it means that it is safe as the outbreak is subsiding since each infected person is transmitting the virus to fewer than one other person. An RO rate above one means the virus is spreading exponentially, with each contagious person infecting more than one other person. An RO of more than
1 is also an indication that hospitals and healthcare systems are vulnerable to becoming overwhelmed. During the fastspreading initial outbreak of the coronavirus in Wuhan, China, the reproduction rate was estimated at around 2.5 , according to a World Health Organization analysis. ${ }^{15}$ Initial estimates of the basic reproduction number $\left(R_{0}\right)$ for COVID-19 in January were between 1.4 and 2.5, but a subsequent analysis has concluded that it may be about 5.7 (with a 95 percent confidence interval of 3.8 to 8.9 ). ${ }^{16}$

India Today Data Intelligence Unit ${ }^{17}$ (DIU) accessed figures of the reproduction rate ' $R$ ' of a virus - similar to RO - calculated by the COV-IND-19 Study Group, School of Public Health, University of Michigan. The study found that on March 24, a day before India went under lockdown, RO was 3.36, which means one infected person was infecting more than three non-infected persons. By the end of Lockdown 1.0, i.e. April 14, it came down to 1.71. On May 3, when Lockdown 2.0 ended, it reduced to 1.46 , and on May 16, it further dipped to 1.27. This means the lockdown brought down the reproductive rate of the virus by almost three times.

Data shows that as of May 16, the seven-day average RO in big states such as Karnataka (1.6), Madhya Pradesh (1.5), Tamil Nadu (1.49), Kerala (1.45) and Maharashtra (1.34) was higher than the national average of 1.27.Even with a high number of cases, Delhi (1.21), Gujarat (1.1) and Uttar Pradesh (1.01) still had a lower R0 than the national average.

However, the use of the national Ro figure has its limitations. Every state within the country has unique circumstances to contend with, with varying number of hotspots and red zones, that require customised containment strategies. That being said, the trajectory of the national RO does certainly provide an indication of whether states' containment strategies are collectively working. Population density is a major factor. The virus spreads much more efficiently in densely populated areas. Mitigation efforts, such as social distancing, school and business closures, and wearing of face masks all help drive the RO number down.

\section{Herd Immunity Threshold (HIT)}

It is well known fact that inherent or herd immunity of an individual plays a vital role in fighting against the harmful pathogens entering the body for its protection. It become very essential in the case of COVID-19, which acts a defense system to protect an individual during the pandemic. Herd immunity threshold is the maximum limit attained by the group of individuals to give protection to the particular disease infection. HIT is calculated as R0-1 divided by RO (RO or R naught is reproduction number). In other words, it can also be described as follows:

- If $\mathrm{RO}$ is 1.5 , then $33 \%$ of population would need to get infected to develop herd immunity.

- If RO is 2 , then $50 \%$ of population would need to get 
infected to develop herd immunity.

- If R0 is 3 , then $66 \%$ of population would need to get infected to develop herd immunity.

- If R0 is 3.5 , then $71.5 \%$ of population would need to get infected to develop herd immunity.

Based on the above calculations, Herd Immunity Threshold (HIT) would reach fast in the states of Maharashtra, Delhi and Gujarat being higher reproduction rate and may be next in Tamil Nadu and West Bengal.

\section{Case Fatality Rate (CFR)}

Case fatality rate is the proportion of deaths out of admitted critical cases. About $5 \%$ of the total cases may become critical cases. Death of critical cases in corona depends on the old age, poor immunity and co-morbid conditions having chronic disease ailments. The deathto-case ratio reflects the number of deaths attributed to COVID-19 divided by the number of diagnosed cases within a given time interval. Based on Johns Hopkins University statistics, the global death-to-case ratio is 6.4 percent $(345,122$ deaths for 5,411,498 cases) as of 25 May 2020.18 Institute for Disease Modeling estimated the IFR as $0.94 \%$ (95\% confidence interval 0.37-2.9), based on data from China. ${ }^{19}$ The University of Oxford's Centre for EvidenceBased Medicine (CEBM) estimated a global CFR of 0.8 to 9.6 percent (last revised 30 April) and IFR of 0.10 percent to 0.41 percent (last revised 2 May), acknowledging that this will vary between populations due to differences in demographics. ${ }^{20}$ The world data depicts the fatality rate as $6.38 \%$ while in India, it was been about $2.93 \%$. The data of CFR in different states is showing different statistics i.e. Maharashtra (3.34), Gujarat (6.70), Delhi (1.79) , Tamil Nadu (0.66), Madhya Pradesh (4.41), West Bengal (7.78), Rajasthan (2.37) and Uttar Pradesh (2.58).

\section{Proportion of Asymptomatic Cases}

The Centre for Evidence-Based Medicine (CEBM) undertook a study to find answer to proportion of people with SARSCOV-2 who are asymptomatic and retrieved 21 reports for analysis. ${ }^{21}$ It was found that about 5 to $80 \%$ of the people testing positive for SARS-CoV-2 may be asymptomatic. It is likely that symptom based screening will miss active cases. Some asymptomatic cases will become symptomatic within a week's time. The children and young adults may be symptomatic.

As per Gol revised version, recovery data shows only $3 \%$ of the patients who test positive require ICU support. it is stated that pre-symptomatic, mild and moderately symptomatic covid-19 cases, who have not had fever for 10 days can not infect others. The discharge policy for covid-19 patients, indicating that positive cases having mild symptoms can be managed without hospitalization. The decision to revise the discharge policy as based on evidence. The changing epidemiological picture indicates that more than $80 \%$ cases are asymptomatic cases and only $20 \%$ appear as symptomatic cases with only $5 \%$ leading into critical cases. But, it becomes some what difficult to understand as how in the susceptible population how this virus played role initially and only the exposure and herd immunity plays an important role in changing the cases into asymptomatic and symptomatic cases. In COVID-19, the young children less than 10 years, pregnant women and old persons above 60 years of age are susceptible to the corona virus.

\section{Doubling Rate or Days}

Despite rising cases of coronavirus in India, the lockdown has been largely successful in containing the intensity of the spread, shows a study by the University of Michigan in the United States. In fact, the intensity of the spread has been reduced to almost a third of what it was prior to the lockdown. While the doubling time in the past 14 days was 11.5 , it has improved to 13.6 days in last three days. The present data indicated the doubling time in India -14 days, USA -33 days, Brazil -13 days, Russia - 18 days, Spain - 47 days, UK - 35 days, Italy - 55 days, France - 49 days, Turkey -37 days. However, epidemiological it is not yet established that at what time/days of doubling days/ interval the disease will flattened and low down gradually. It may varied in different containment zones or hot spots.

\section{Containment Strategy}

Initially, the entry of corona in India is through the international passengers coming from COVID-19 affected countries. The thermal screening was made mandatory and diagnosis was done for the patients with cough, soar throat pain and fever. The same were quarantine by the health authorities for a period of 14 days. Screening at all the international airports was started by the airport health officers in country. Initially, the diagnosis was done for first cases and second contacts. ${ }^{22-23}$ It is very difficult to undertake surveillance in the whole population. Epidemiologically, it is difficult to say and decide about the sampling population targeted for testing unless the disease cases are found. A cluster-containment strategy is mainly being adopted, similar to how India contained previous epidemics, as well as "breaking the chain of transmission".

Out of 733 districts in the country, 130 districts were in red zone, 284 districts in orange zone and 319 districts in the green zone taking into consideration incidence of cases of COVID-19, doubling rate and surveillance feedback.

Due to the timely lockdown, the nation could get time to make preparations for infrastructure for fighting against corona. India could reach 80,000 cases in 106 days while other countries namely UK, Italy, Spain, Germany and US tool only 44-66 days to reach this figure. There are 
presently 916 dedicated Covid-19 hospitals with 1,80,473 beds - 161169 isolation and 19,304 ICU and 2044 dedicated hath centres with $1,28,304$ beds $(117,775$ isolation beds and 10,529 ICU beds alongwith 9,536 quarantine centres and 6,309 care centres with 5,64,632 beds available in the country. The daily testing capacity has been enhanced to more than 1 lakh tests through 373 govt. and 152 private laboratories. About 90.22 lakhs N-masks and 53.98 lakh of PPEs have been provided to all the states and UTs by Gol.

\section{Conclusion}

There have been several pro-active actions to deal with the deadly corona transmission in the country at the governmental level. Some of the key actions with regard to prevention and control has been well depicted in some recent publication. Epidemiology of Covid-19 is observed to be changing day by day with different evidences and publications in terms of its transmission, clinical spectrum, susceptible population, severity, recovery rate, reproduction rate and doubling number/ rate etc. Other epidemiological indicators such as detection rate per million population or positivity rate, case fatality rates are also being found Varying with the different states/geographical areas. It is now difficult to understand the dynamics of Covid-19 transmission in the situation when many relaxations have been declared during lockdown 4 . The families are now at risk when one person has started going out due to relaxations in lockdown. More, precautions are to be followed by the family members. However, the only caution remains that one has to take that regular washing of hands, use of masks at workplace and principle of social distancing by 2 metre, which will be help in breaking the chain of transmission for this deadly corona virus.

\section{Conflicts of Interest: None}

\section{References}

1. WHO. Coronavirus very likely of animal origin, no sign of lab manipulation: WHO. Reuters 21 April 2020. Retrieved 23 April 2020.

2. Statement on the second meeting of the International Health Regulations (2005) Emergency Committee regarding the outbreak of novel coronavirus (2019nCoV). World Health Organization (WHO). 30 January 2020. Archived from the original on 31 January 2020. Retrieved 30 January 2020.

3. WHO Director-General's opening remarks at the media briefing on COVID-19-11 March 2020. World Health Organization. 11 March 2020. Retrieved 11 March 2020.

4. Q\&A on coronaviruses (COVID-19). World Health Organization (WHO). 17 April 2020. Archived from the original on 14 May 2020. Retrieved 14 May 2020.

5. How COVID-19 Spreads". Centers for Disease Control and Prevention(CDC). 2 April 2020. Archived from the original on 3 April 2020. Retrieved 3 April 2020.

6. Home | Ministry of Health and Family Welfare | GOI". mohfw.gov.in. Retrieved 21 May 2020.

7. India's case count crosses 100,000 , Delhi eases restrictions: Covid-19 news today. Hindustan Times. 19 May 2020. Retrieved 20 May 2020.

8. In biggest single-day spike, India records over 5,611 Covid-19 cases. Hindustan Times. 20 May 2020. Retrieved 20 May 2020.

9. Coronavirus pandemic (COVID-19) in India. Our World in Data. Retrieved 20 May 2020.

10. Infections over 1 lakh, five cities with half the cases: India's coronavirus story so far. The Week. Retrieved 20 May 2020.

11. Arons MM, Hatfield KM, Reddy SC, Kimball A, James A, Jacobs JR et al. Presymptomatic SARS-CoV-2 Infections and Transmission in a Skilled Nursing Facility. The New England Journal of Medicine: NEJMoa (April 2020) 2008457. DOI:10.1056/NEJMoa 2008457. PMC 7200056. PMID 32329971.

12. Coronavirus. World Health Organization (WHO). Retrieved 4 May 2020.

13. Coronavirus Disease 2019 (COVID-19). U.S. Centers for Disease Control and Prevention (CDC). 11 February 2020. Retrieved 19 April 2020.

14. Symptoms of Coronavirus. U.S. Centers for Disease Control and Prevention (CDC). 20 March 2020. Archived from the original on 30 January 2020.

15. Rai B, Shukla A, Dwivedi LK. COVID-19 in India: Predictions, Reproduction Number and Public Health Preparedness. medRxiv preprint. 2020. DOI: https:// doi.org/10.1101/2020.04.09.20059261.

16. Statement on the meeting of the International Health Regulations (2005) Emergency Committee regarding the outbreak of novel coronavirus 2019 (n-CoV) on 23 January 2020. World Health Organization (WHO). Retrieved 9 April 2020.

17. Data Intelligence Unit, India Today Group.

18. COVID-19 Dashboard by the Center for Systems Science and Engineering (CSSE) at Johns Hopkins University (JHU)". ArcGIS. Johns Hopkins University. Retrieved 25 May 2020.

19. 2019-nCoV: preliminary estimates of the confirmedcase-fatality-ratio and infection-fatality-ratio and initial pandemic risk assessment. institutefordiseasemodeling. github.io. Retrieved 6 May 2020.

20. Lazzerini M, Putoto G. COVID-19 in Italy: momentous decisions and many uncertainties. The Lancet Global Health. 2020; 0(5): e641-e642. DOI:10.1016/S2214109X(20)30110-8. PMC 7104294. PMID 32199072.

21. Heneghan C, Brassey J, Jefferson T. COVID-19: What proportion are asymptomatic?. Centre for EvidenceBased Medicine 2020. Retrieved 17 May 2020. 
22. Singh SK, Jain SK, Sharma SN. Prevention and Control of COVID-19 in Indian Perspective. Epidemiology International 2020; 5(1): 32-38.

23. Sharma SN, Singh SK. Challenges and Threats due to deadly corona virus in India and dealing it with social vaccine (distancing) - the only weapon. Journal of Communicable Diseases 2020; 52(1): 7-13. 